\title{
First report of a newly detected potyvirus, Commelina mild mosaic virus, infecting Commelina spp. in Australia
}

\author{
Linda Zheng • Mark Gibbs • Adrian Gibbs • \\ Brendan Rodoni
}

Received: 13 September 2010 / Accepted: 9 February 2011 /Published online: 15 March 2011

(C) Australasian Plant Pathology Society Inc. 2011

\begin{abstract}
In 2007, a sample of scurvy weed (Commelina cyanea) showing mild mosaic leaf symptoms was collected from Rosedale, New South Wales, Australia. From this plant we obtained the NIb/CP gene sequence of a previously unrecognised potyvirus, for which we have suggested the name Commelina mild mosaic virus (CMMV). Sequence analysis indicated that CMMV has no close relationship to any potyvirus that has been sequenced previously. The relationship of this species to other previously identified, but not sequenced potyviruses isolated from Commelina spp. in other countries is also not known due to a lack of nucleotide sequence data. This is the first time a potyvirus has been reported to infect a native Commelina species in Australia.
\end{abstract}

Keywords New and emerging $\cdot$ Degenerate primers $\cdot$ Plant virus detection · Plant virus diagnostics · Universal primers

In 2007, a sample of native scurvy weed (Commelina cyanea) showing mild mosaic leaf symptoms was collected from

\footnotetext{
L. Zheng $(\bowtie) \cdot$ B. Rodoni

VIC 3156, Australia

e-mail: linda.zheng@dpi.vic.gov.au

L. Zheng $\cdot$ B. Rodoni

M. Gibbs

Curtin,

Canberra, ACT 2605, Australia

A. Gibbs

7 Hutt Street,

Yarralumla, ACT 2600, Australia
}

Victorian Department of Primary Industries,

Private Bag 15, Ferntree Gully Delivery Centre,

Cooperative Research Centre for National Plant Biosecurity,

LPO Box 5012, Bruce ACT 2617, Australia coastal woodland at Rosedale, a settlement near Batemans Bay on the south coast of New South Wales, Australia. Commelina cyanea, 'scurvy weed', was used as an antiscorbutic by the first European settlers of these regions two centuries ago and it is widespread throughout the eastern coastline of Australia, mainly in forests and woodlands of Queensland, New South Wales and Northern Territory.

Nucleic acids were extracted from the leaf tissue of the sample and tested for the presence of potyviruses using reverse transcription PCR (RT-PCR). The sample tested positive for potyvirus infection using two sets of universal potyvirus primers "NIb2F-3R" (Zheng et al. 2010) and "Potyvirid 1-2" (Gibbs and Mackenzie 1997a, b). The "NIb2F-3R" primers were used due to their wide range of detection and generated a 350 bp PCR product from the RNA replicase $(\mathrm{NIb})$ gene of the potyvirus genome. The "Potyvirid" primers amplified a larger PCR product of $1.62 \mathrm{~kb}$ in length, spanning part of the NIb gene, the entire coat protein (CP) gene and the $3^{\prime}$ untranslated region (UTR) from the potyvirus genome, which is often used for potyvirus species demarcation. Consequently, this larger PCR product was cloned into the vector pGEM-T using the manufacturer's protocols (Easy II Vector System, Promega Corporation, Madison, WI, USA) and three clones containing the inserts were sequenced in both directions using the Big dye 3.1 kit (Applied Biosystems, California, USA). A consensus sequence of $1.62 \mathrm{~kb}$ (GenBank accession HQ225836) was created from the six sequences obtained and used to search GenBank using BLASTN (Altschul et al. 1990).

An alignment 1,166 bp long between a part of the $1.62 \mathrm{~kb}$ sequence and a nucleotide sequence from the Christmas bell potyvirus (GenBank accession: EF427894.1), with 67\% (781/1166) sequence identity, suggested that the $1.62 \mathrm{~kb}$ sequence was of viral origin. No other significant similarity to sequences was found using BLASTN. The Christmas bell potyvirus is a species that has not yet been recognised by the 
Fig. 1 Consensus MinimumEvolution tree of 57 potyviruses inferred from an alignment of their nucleotide sequences from the NIb, CP and 3'-UTR region targeted by the "Potyvirid" primers and rooted using the homologous ryegrass mosaic rymovirus sequence

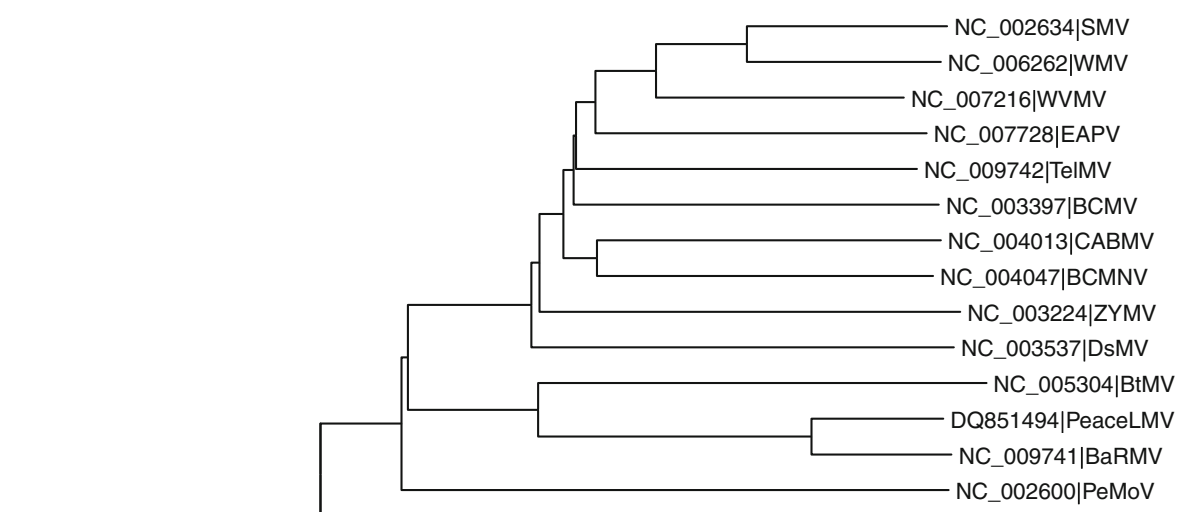

NC_008824|NDV
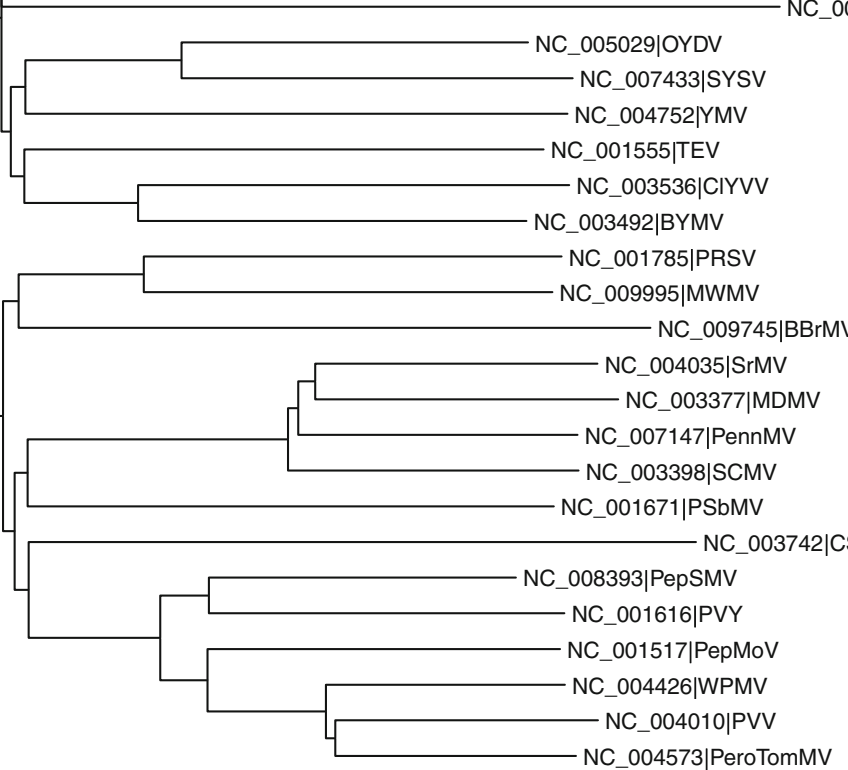

NC 009744|WildTomMV

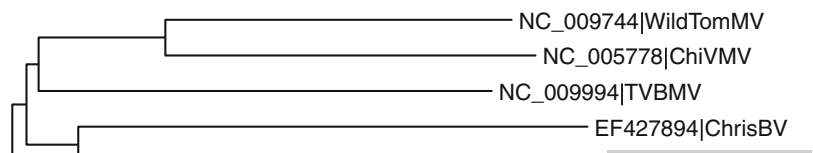

- HQ225836|CMMV

DQ436918|IMMV

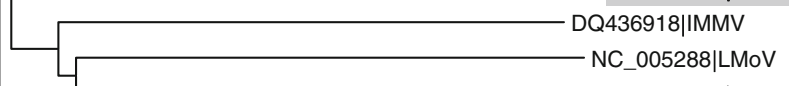

- NC_004011|LYSV

- NC_004039|PVA

- NC_001841|SPFMV

- NC_007913|KMV

NC_001445|PPV

NC_007180|TFMV

- NC_003605|LMV

NC_000947|JYMV

- NC_002509|TuMV

NC_003399|ScMV

NC_005028|PLDMV

NC_008028|DapMV

NC_001768|TVMV

NC_003606|JGMV 
International Committee on Taxonomy of Viruses but is placed with potyviruses in GenBank's unofficial taxonomy.

A translation of the nucleotide sequence showed it contained a long open reading frame, as would be expected from a potyvirus genome, which encoded a 540 amino acid

Fig. 2 Consensus MinimumEvolution tree inferred from 57 amino acid sequences translated from the $\mathrm{NIb}$ and $\mathrm{CP}$ region of the potyvirus genome targeted by the "Potyvirid" primers and rooted with the homologous ryegrass mosaic rymovirus sequence (aa) residue protein sequence. The deduced protein sequence was used to search the GenBank protein database using BLASTX. Almost all of the protein sequence, 490 aa, aligned with a region of the polyprotein of the potyvirus Iris mild mosaic virus (IMMV; ABD98799.2) with a

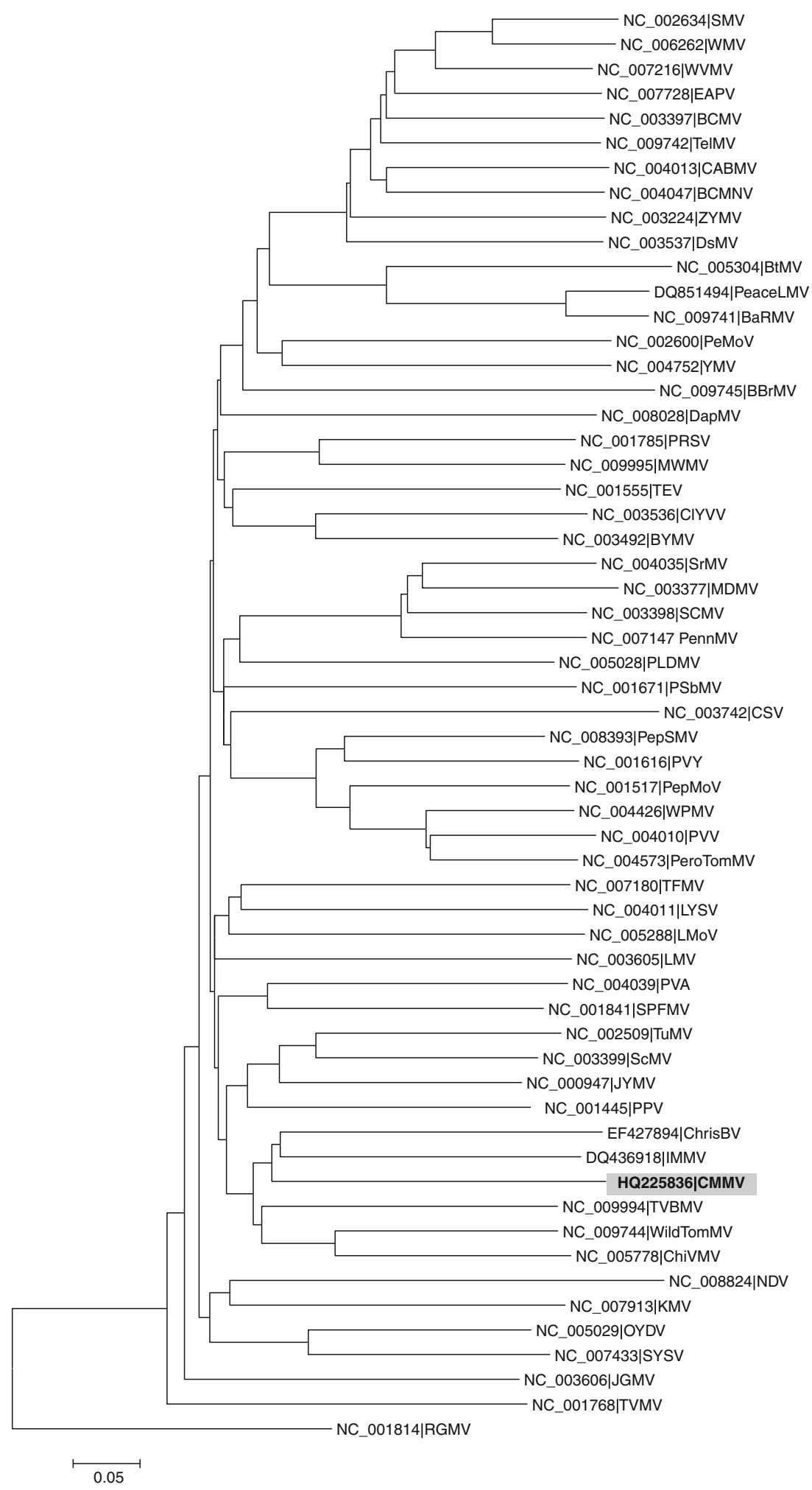


sequence identity score of $61 \%(302 / 490)$ and a similarity score, based on amino acid residues with similar properties, of $75 \%(369 / 490)$.

To further investigate the relationship of the unrecognised virus with other species within the Potyvirus genus, phylogenetic analyses were done using the nucleotide and translated amino acid sequences of Christmas bell potyvirus, IMMV and 54 distinct species representing all of the major clusters of potyvirus. Two trees were calculated from the nucleotide and amino acid alignments using the Minimum-Evolution method (Rzhetsky and Nei 1992) and MEGA version 4 (Tamura et al. 2007). Bootstrap analyses were done using 1,000 replicate samples from the alignments and bootstrap consensus trees were found (Felsenstein 1985). Branches corresponding to partitions reproduced in less than $50 \%$ bootstrap replicates in both trees were collapsed. For the nucleotide tree, sequences from the NIb, CP and 3'-UTR regions targeted by the "Potyvirid" primers were used. For the amino acid tree, only the sequences from the NIb and CP region of the potyvirus genomes were used because the $3^{\prime}$-UTR does not encode a protein. The reference sequences from Ryegrass mosaic virus (type species of genus Rymovirus; NC_001814) were used as outgroups to root both trees (Figs. 1 and 2).

In the nucleotide tree, the sequence from the unrecognised virus was placed on a long branch in the same clade as Christmas bell potyvirus (Fig. 1). In the amino acid tree, the sequence from the unrecognised virus was placed in a cluster, but not the same clade, with Christmas bell potyvirus and IMMV (Fig. 2).

Both trees suggest that the virus is a distinct potyvirus species, as do our results from database searches and alignments. The nucleotide and amino acid sequences of the unrecognised virus were only $38.7-55.5 \%$ and $42.4-$ $59.6 \%$ identical, respectively, to those of other potyvirus species included in the alignment. These identity scores are significantly lower than those recommended to distinguish potyvirus species (Adams et al. 2005), being $76-77 \%$ for nucleotides and $82 \%$ for amino acids, based on alignments of coat protein sequences.

Six RNA virus species have been reported to naturally infect Commelina spp., four probably belonging to the genus Potyvirus, one belonging to the genus Bromovirus and one belonging to the genus Cucumovirus (Table 1). Of the potyviruses reported to infect Commelina species, none is known to occur in Australia and sequence from not one is available in GenBank, the latest one isolated remains uncharacterised (Grisoni et al. 2006). The relationship of this virus to other previously identified, but not sequenced potyviruses isolated from Commelina spp. is therefore difficult to determine without sequence information.

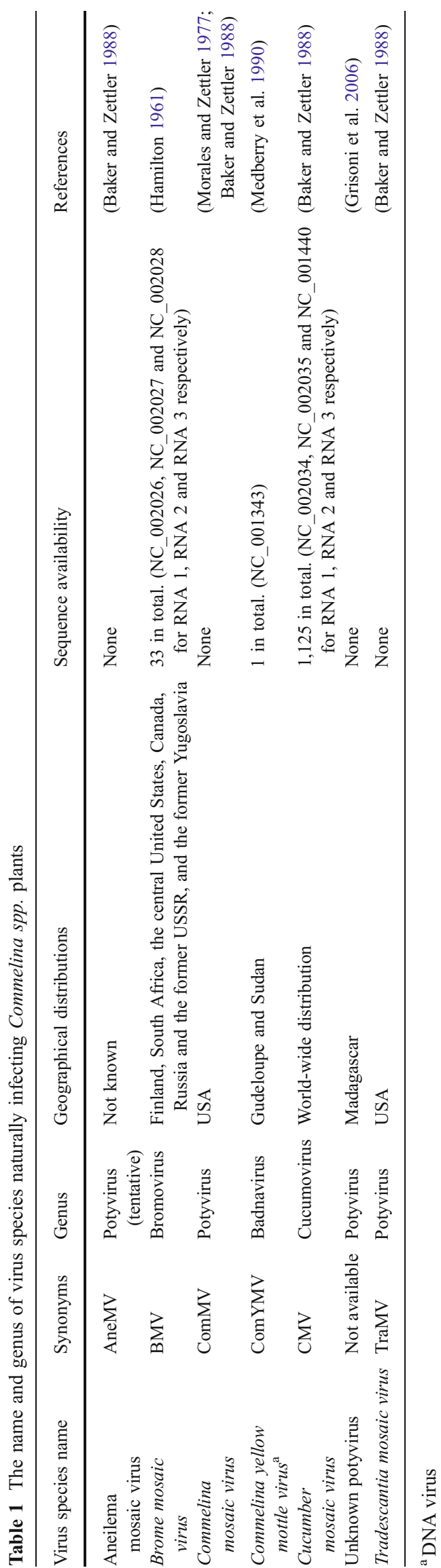


Commelina cyanea, 'scurvy weed', is native to Australia and at the time of writing, this is the first report of a potyvirus infecting a Commelina sp. in Australia. It seems likely, given the geographic location and novel host, that the virus differs from all the potyviruses previously isolated from Commelina spp. and it is a newly recognised species. We suggest the name 'Commelina mild mosaic virus' (CMMV) for this virus.

Interestingly, CMMV does not belong to the bean common mosaic virus lineage like most other potyviruses isolated from Australian native plants (Gibbs et al. 2008). Its closest relatives are Christmas bell potyvirus and IMMV, both of which have not been reported in Australia. IMMV was originally isolated from Iris ssp. in Netherlands, but it is now present in most commercially important cultivars and probably distributed worldwide (http://www.ictvdb.org/ ICTVdB/00.057.0.01.033.htm). There are currently four IMMV sequences available in GenBank and the translated amino acid of one of the two New Zealand isolates (DQ436918) matched closest to CMMV. No other significant relationship can be elucidated from these two species.

Similarly, little insight can be gained from the relationship between CMMV and Christmas bell potyvirus due to the lack of host range, serological and transmission data for both species. The only isolate of Christmas bell potyvirus was isolated from Sandersonia aurantiaca, 'Christmas bell', from Taiwan and other than its nucleotide sequences deposited in GenBank, no other biological data exist for this tentative potyvirus species.

Further sampling of the CMMV population and biological experiments will be required to determine whether the virus is found in any other plant species and how the virus relates to other Australian potyviruses.

\section{References}

Adams MJ, Antoniw JF, Fauquet CM (2005) Molecular criteria for genus and species discrimination within the family Potyviridae. Arch Virol 150:459-479

Altschul SF, Gish W, Miller W, Myers EW, Lipman DJ (1990) Basic local alignment search tool. J Mol Biol 215:403-410

Baker CA, Zettler FW (1988) Viruses infecting wild and cultivated species of the Commelinaceae. Plant Dis 72:513-518

Felsenstein J (1985) Confidence limits on phylogenies: an approach using the bootstrap. Evolution 39:783-791

Gibbs A, Mackenzie A (1997a) A primer pair for amplifying part of the genome of all potyvirids by RT-PCR. J Virol Meth 63:9-16

Gibbs A, Mackenzie A (1997b) Erratum to "A primer pair for amplifying part of the genome of all potyvirids by PT-PCR" [J. Virol. Methods 63 (1997) 11]. J Virol Meth 65:317

Gibbs AJ, Mackenzie AM, Wei KJ, Gibbs MJ (2008) The potyviruses of Australia. Arch Virol 153:1411-1420

Grisoni M, Moles M, Farreyrol K, Rassaby L, Davis R, Pearson M (2006) Identification of potyviruses infecting vanilla by direct sequencing of a short RT-PCR amplicon. Plant Pathol 55:523529

Hamilton RI (1961) Properties of brome mosaic virus and its related antigens. Virology 15:452-464

Medberry SL, Lockhart BEL, Olszewski NE (1990) Properties of Commelina yellow mottle virus's complete DNA sequence, genomic discontinuities and transcript suggest that it is a pararetrovirus. Nucleic Acids Res 18:5505-5513

Morales FJ, Zettler FW (1977) Characterization and electron microscopy of a Potyvirus Infecting Commelina diffusa. Phytopathology 67:839

Rzhetsky A, Nei M (1992) A simple method for estimating and testing minimum evolution trees. Mol Biol Evol 9:945-967

Tamura K, Dudley J, Nei M, Kumar S (2007) MEGA4: molecular evolutionary genetics analysis (MEGA) software version 4.0. Mol Biol Evol 24:1596-1599

Zheng L, Rodoni BC, Gibbs MJ, Gibbs AJ (2010) A novel pair of universal primers for the detection of potyviruses. Plant Pathol 59:211-220 